\title{
Author Correction: Record thermopower found in an IrMn-based spintronic stack
}

Sa Tu, Timothy Ziman (D), Guoqiang Yu (D), Caihua Wan, Junfeng Hu B , Hao Wu D, Hanchen Wang (D), Mengchao Liu, Chuanpu Liu, Chenyang Guo, Jianyu Zhang, Marco A. Cabero Z. (1), Youguang Zhang, Peng Gao (D), Song Liu, Dapeng Yu, Xiufeng Han (1), Ingrid Hallsteinsen, Dustin A. Gilbert (1D, Mamoru Matsuo, Yuichi Ohnuma, Peter Wölfle, Kang L. Wang (1D, Jean-Philippe Ansermet, Sadamichi Maekawa \& Haiming Yu (D)

Correction to: Nature Communications https://doi.org/10.1038/s41467-020-15797-6, published online 24 April 2020.

The original version of this Article contained errors in the author list and affiliations.

Author Mamoru Matsuo affiliated with Kavli Institute for Theoretical Sciences, University of Chinese Academy of Sciences, Beijing 100190, China and RIKEN Center for Emergent Matter Science (CEMS), Wako 351-0198, Japan was inadvertently omitted.

Author Yuichi Ohnuma affiliated with Kavli Institute for Theoretical Sciences, University of Chinese Academy of Sciences, Beijing 100190, China was inadvertently omitted.

These have now been corrected in both the PDF and HTML versions of the Article.

Published online: 14 May 2020

\footnotetext{
(c) Open Access This article is licensed under a Creative Commons Attribution 4.0 International License, which permits use, sharing, adaptation, distribution and reproduction in any medium or format, as long as you give appropriate credit to the original author(s) and the source, provide a link to the Creative Commons license, and indicate if changes were made. The images or other third party material in this article are included in the article's Creative Commons license, unless indicated otherwise in a credit line to the material. If material is not included in the article's Creative Commons license and your intended use is not permitted by statutory regulation or exceeds the permitted use, you will need to obtain permission directly from the copyright holder. To view a copy of this license, visit http://creativecommons.org/licenses/by/4.0/.
}

(C) The Author(s) 2020 